The Journal of Private Enterprise 24(2), 2009, 1-19

\title{
Making Room for Business Ethics: Rights as Metanorms for Market and Moral Values
}

\author{
Douglas B. Rasmussen
}

St. John's University

\section{Douglas J. Den Uyl}

Liberty Fund

\begin{abstract}
Business ethics need not be business bashing if systemic criticisms of the institutions that define capitalism are differentiated from criticisms of the immoral activities of particular persons and firms. The former requires an examination of the ethical principles (individual rights) that give support and meaning to capitalist institutions, and the latter requires an examination of the purpose of business (pursuit of profit). Neither the moral significance of the institutions of capitalism nor the activities of persons and firms can be properly understood without the realization that ethical principles are not of one type - that "equinormativity" is false.
\end{abstract}

JEL Codes: A12, A13, M14

Keywords: Business ethics; Capitalism; Liberalism; Individual rights; Metanorms

A social system is a set of moral-political-economic principles embodied in a society's laws, institutions, and government, which determine the relationships, the terms of association, among the men living in a given geographical area.... Capitalism is a social system based on the recognition of individual rights, including property rights, in which all property is privately owned. -Ayn Rand, "What is Capitalism?" Capitalism: The Unknown Ideal

\section{Introduction}

We are probably all familiar with the hackneyed remark: "'Business ethics,' there's an oxymoron for you." Sometimes it is even said that 'profit' is a four-letter word. Indeed, much of what 
passes for business ethics today is really a case of business bashing. ${ }^{1}$ But does business ethics have to be business bashing? We think not. Yet, to see how this is possible we need to realize that many of the criticisms of business activity that we find in our culture (and in the business ethics literature) are not criticisms of particular persons and firms for conduct that violates basic canons of morality. They are not, for example, criticisms of cases in which people lie or cheat; give up on personal integrity, or any personal responsibility; or simply forgo the pursuit of excellence in any form. Rather, these criticisms are systemic in nature - that is, they aim to analyze the very institutions that define and sanction business activity. ${ }^{2}$ We find here criticisms of such institutions as private property, the sanctity of contracts, free exchange, and the pursuit of profit.

There is, of course, nothing sacrosanct about these institutions. They can and ought to be examined. Yet, the point is that once this sort of analysis begins, it should be recognized that one is engaging in a critique that is not so much concerned with the particular practices of persons and firms but with the system itself. It is a critique that, properly speaking, belongs to the realm of political philosophy.

Now, this may seem a trivial observation, because it is quite common for business ethics texts to include discussions of questions of justice and some selections from representative views of justice for example, selections from Rawls, Nozick, and usually some communitarian or socialist-leaning thinker. Furthermore, there is usually some discussion of basic approaches to questions of

1 Tibor R. Machan and James E. Chesher discuss this phenomenon and differentiate business bashing from business ethics. (See Machan and Chesher, 2002, p.xii and also Machan, 2007.)

2 Many business ethics texts (see, for example, Beauchamp and Bowie, 2003; Donaldson, Werhane, and Cording, 2001; Shaw and Barry, 2006) are filled with criticisms that are systemic in character, for instance: a capitalist system of private property and free exchange fails to embody the ideals of "economic" or "social" justice; capitalism fails to promote the common good or reflect our most important social values; the function of business activity ought not to be simply to make a profit; the job-market in capitalism fails to provide fulfilling (or non-alienating) work; and the ethos of capitalism promotes (or allows for) moral mediocrity. Indeed, Machan and Chesher observe that "most texts concern not so much the occasional difficulties that arise in business but discuss its very essence, such as making profits, owning shares, employing workers, and trading on the stock market" (Machan and Chesher, 2002, p.xi). (For some particularly egregious examples of this systemic critique, see: Donaldson, 1982; and Brock, 1998.) 
normative ethics in which we find consequentialist, deontological, and sometimes virtue-ethics approaches outlined. However, the problem here is that generally some important differences are being ignored. Particularly, it is seldom noted whether one is talking of justice for persons or for institutions. Moreover, hardly ever is there any consideration of what kinds of institutions are involved and how that might be important to not only the answers that are offered but to determining the questions that need to be asked. Indeed, texts generally fail to discuss the differences between justifying and evaluating the political/legal institutions that define and sanction business activity and justifying and evaluating the conduct of the people and organizations that work within their orbit. ${ }^{3}$

\section{If one is to properly assess the morality or ethics of business activity, then one needs to understand and appreciate the ethical basis of the political/legal institutions in which they function.}

We do not regard this thesis as particularly controversial, but we do think that what it involves has not been fully appreciated by either the critics or the defenders of business activity. To appreciate the importance of this thesis, it must be made clear what is meant by that most abused word, "capitalism." To begin with, we understand it to refer to an economic and social system that is defined in terms of the institutions of private property, sanctity of contract, free exchange, and the pursuit of profit. Yet, there is more to understanding capitalism than this - one needs to consider the particular sort of ethical norm that underlies and supports these institutions. We will illustrate with three examples.

A. Even though there might be a large demand for this service and thus a great opportunity for profit, "Murder Incorporated" is not regarded in a capitalistic system as a legitimate business firm. It is considered criminal and not allowed to operate legally.

B. The term "profit" does not mean merely a return on an exchange that is over costs. It involves a free exchange. The gunman's offer, "Your money or your life" is not considered a free exchange - even though most of us would prefer remaining alive to losing our money. Making such offers is regarded as criminal and legally prohibited.

\footnotetext{
${ }^{3}$ We illustrate and discuss this tendency below, pp. 13-14.
} 
C. If Mary obtains William's property through an exchange but knowingly and willingly plans or refuses to fulfill the terms of the exchange, then Mary's possession of William's property is a taking of William's property without William's consent, because Mary possesses William's property on terms other than those to which William agreed. Such actions on Mary's part are viewed as criminal fraud and legally prohibited.

Clearly, Murder Incorporated, the gunman, and Mary are behaving not only in a morally wrong manner, but they are also engaging in activities that fail to qualify as examples of capitalist activities. They fail to represent what Nozick called "capitalist acts between consenting adults" (Nozick, 1974, p.163). But even more, they are engaging in activities that destroy the very institutions that define a capitalist socio-economic system.

There is, then, an ethical dimension to understanding capitalism as the particular type of socio-economic system it is. Moreover, it is an ethical dimension that gives paramount and fundamental importance to the legal protection of the institutions of private property, free exchange, sanctity of contract, and the pursuit of profit. The most powerful way to express this ethical dimension is to say that the activities of Murder Incorporated, the gunman, and Mary are violating the rights of the persons with whom they are involved. Rights define and sanction the central institutions of capitalism. For the purposes of this essay, we will say, then, that ideally speaking the ethical norm that defines what kind of activities may legally function in a capitalist socio-economic system is individual rights. ${ }^{4}$

The concept of individual rights is complex, but it can be expressed as follows. Individual human beings have a basic, negative, moral right to liberty. 'Right' is used here to refer to a claim or entitlement that individuals have on how others will treat them. 'Moral' means that this treatment ought to exist but not necessarily does exist. 'Negative' refers to the type of treatment that others owe individuals - that is, they may not use individuals without their consent. Specifically, persons are prohibited from initiating, or threatening to initiate, physical force in any or all its forms against

\footnotetext{
${ }^{4}$ We are aware, of course, that there has been for some time a growing movement away from this understanding of capitalism and that even in the United States what passes for a capitalist socio-economic system now is really an instance of the mixed economy in which many business interests routinely seek, obtain, and use government coercion for their own advantage. (See Bradley, Jr., 2009, p.3.)
} 
other persons. This right is considered basic in the sense that it is not founded on any other right and is the source for other, derivative rights - that is, rights that flow from the exercise of this basic right.

An individual's basic right to liberty is also understood to entail two corollary basic rights: the right to life and the right to private property. The former is the right to live one's life according to one's own choices, not to be physically compelled or threatened. The latter involves, fundamentally, not the right to an object, but the right to an action and the consequence of producing or earning that object. So understood, this implies that the lives and resources, as well as conduct, of individuals may not be used or directed to purposes to which they have not consented. These rights apply to every human person, but they also require a legal system for their actual implementation.

Further, given that individuals have such basic rights, then they may not be coercively prohibited from doing what is morally wrong. People ought to be free to choose the morally wrong course of action. Physical compulsion and coercion - the boundaries of which are determined by individual rights - may be used ultimately only in defense against, or in response to, the exercise of physical force or coercion, which is generally understood to include extortion and fraud.

These rights, on the one hand, provide wide legal latitude for individuals to exercise their lifestyle choices. Economically, Nozick expressed this idea when, as already noted, he talked of "capitalist acts between consenting adults," but this general idea also extends well beyond the economic arena to the choices of people to hold false moral and religious beliefs and to engage in morally wrong activities. On the other hand, since these rights only require that others refrain from initiating or threatening to initiate physical force in any or all of its forms, this means that those who do not approve of the beliefs and activities of others are free to disassociate themselves from them. They have the freedom to refuse not only to support these beliefs and activities but also to criticize them and to attempt to persuade people to change their ways. Individual rights thus require toleration, but they do not require support, approval, or acceptance of what people choose to believe or do. They only require 
acceptance of their right to choose - that is, not to have their lives, conduct, or resources nonconsensually used or directed. ${ }^{5}$

\section{Capitalism is not only an economic and social system; it is also a certain type of political/legal order. It is a liberal order. ${ }^{6}$}

As we noted at the beginning of these remarks, much of the criticism of business activity is systemic and amounts to the type of criticism that usually takes place in political philosophy. Therefore, it is important to be clear regarding just what the basic issues of political philosophy are as well as in what the justification for individual rights consists. However, a full analysis of these issues and the argument for individual rights is far beyond what can be achieved in an essay of this size. So, in what follows we will make extensive use of the analysis and argument that was developed in our book, Norms of Liberty (Rasmussen and Den Uyl, 2005), and refer the reader to that work for a more complete account and defense of what is said here.

Accordingly, the basic issues of political philosophy may be expressed in two questions:

Is there a connection between the ethical and the political/ legal orders, and, if so, what is the nature of the connection between them?

If there is no ethical basis for a society's political/legal order, then, its legitimacy is, to say the least, dubious. Of course, it might be the case that there can be no morally legitimate political/legal orders. Yet, even if it is granted that there is some connection between the two orders, it certainly should not be assumed at the outset that there is a direct or isomorphic relation between the two, much less an identity. To say that some activity $\mathrm{X}$ is morally right or good and ought to be done does not, by itself, imply that doing $\mathrm{X}$ ought to be politically/legally required. Further, to say that doing $\mathrm{X}$ is morally wrong and ought not to be done does not, by itself, imply that doing $\mathrm{X}$ ought to be politically/legally prohibited. Further, these claims are obviously not semantically equivalent. Indeed, Aquinas notes that

\footnotetext{
${ }^{5}$ The most basic way by which one's life, conduct, and resources are used or directed without one's consent is through the use of physical force. (See Rasmussen and Den Uyl, 2005, p.89 n15.)

${ }^{6}$ Of course, we mean "liberal" in the classical sense - as expressed, for example, by John Locke or Frederic Bastiat.
} 
there is a difference between demands of justice that are morally binding and demands of justice that are morally and legally binding (Aquinas, 1981, II-III, 23 ad 1 and II-II, 80, ad 1). It thus cannot be simply assumed that politics is ethics writ large.

There needs to be something that connects the ethical and the political/legal orders. Indeed, this is, de jure, the fundamental datum explanandum of political philosophy, and it is incumbent on the political philosopher to show what justifies moving from one order to the next. This cannot merely be assumed. Because of the prima facie difference between moral and political claims that was noted above, the onus of proof is on the person who seeks to move from the ethical to the political/legal. Without such proof, there is then no ethical justification for a political/legal order. ${ }^{7}$

Determining the nature of the connection between the ethical order and the political/legal order is a question that has had different answers throughout the history of political philosophy. Broadly speaking, there have been two traditions of answers: an ancient and a modern one. The ancient tradition, working with the idea of a "polis" and a more or less monistic understanding of the human good, does not distinguish between the ethical order and political/legal order. Statecraft is primarily a version of soulcraft that is to say, the function of the political is "to make men moral." The modern tradition, working with the idea of a society that extends far beyond that of a "polis" as well as a more pluralistic view of the human good, rejects the idea that statecraft is soulcraft and makes securing peace and liberty the primary aim of the political/legal order (Rasmussen and Den Uyl, 2005, Ch. 2-3).

Liberalism belongs to the modern tradition of political philosophy. Indeed, what both the critics and proponents of liberalism do not often realize is that the essential uniqueness of liberalism as a political theory is its divestment of substantive morality from politics. Liberalism stands in direct opposition to how politics has been conceived since Plato, as the effective institutionalization of the ethical. Liberalism's true uniqueness is its

\footnotetext{
${ }^{7}$ These last two paragraphs are taken with minor changes from Norms of Liberty (Rasmussen and Den Uyl, 2005, p.85).

${ }^{8}$ Aquinas distinguishes between the two orders, but ultimately this is not based on some principled difference between them but simply the practical difficulties in achieving the common good of the political community.
} 
endeavor to distinguish politics from morality in the same way it is generally recognized to have done with respect to theology.

The reasons for liberalism distinguishing politics from ethics are complicated and more than we can discuss at this time. Moreover, many of liberalism's proponents have not adequately considered all that is involved in justifying this distinction. Nonetheless, a good way to get an accurate understanding of liberalism is to consider a task or problem that has seldom been considered by any other political tradition. Thus, this task is called "liberalism's problem" because liberalism has been, mostly, the only political tradition to appreciate its fundamentality and importance. This problem is expressed as a set of interrelated questions. We have expressed this as follows:

How is the appropriate political/legal order - the order that provides the overall structure to the social/political context to be determined? What is its ethical basis? Since the structure provided by the political/legal order will rule over all equally, how can the universalism of political/legal structural principles square with the pluralistic and self-directed character of human well-being? Hence, how is it possible to have an ethical basis for an overall or general social/political context - a context that is open-ended or cosmopolitan - that will not require, as a matter of principle, that one form of human well-being be preferred to another? How, in other words, can the possibility be achieved that various forms of well-being will not be in structural conflict? (Rasmussen and Den Uyl, 2005, p.271, emphasis added and minor changes made.)

Clearly, this problem presupposes the following: That society is not (and should not be confined to) simply a "polis." That there is a great degree of diversity to be found in the well-being of different persons and that much of this comes from their communities and cultures. That there can be conflicts between forms of well-being. That self-direction is fundamental and crucial to the activity of human well-being or moral activity. That the aim of the political/legal order is to have principles that apply to all equally, and that any conflicts between forms of well-being should not be a structural feature of any social system. All these claims are quite plausible. 
Nonetheless, they require support, and such support can be found in Norms of Liberty.

The reason it is not necessary for us to provide such support here is because our task is not so grand. We want merely to show that if one takes liberalism's problem as a fundamental and crucial one, then it becomes possible to see not only how liberalism can distinguish the political/legal order from the ethical but also how individual rights are a different type of ethical norm. This conclusion will in turn make a difference to how we understand and defend the institutions that define capitalism and provide the context for business activity. Finally, it will make a difference to how we conceive "business ethics."

Assuming that liberalism's problem is both fundamental and crucial, then how does one find the ethical basis for its solution? The criteria ${ }^{9}$ that need to be met to determine the ethical basis for a solution to liberalism's problem are as follows:

a. It must not structurally prejudice the overall social context more toward some forms of human well-being than others;

b. it must be universal or equally applicable to all forms of human well-being - that is, it must be social in the open-ended or cosmopolitan sense;

c. it must be concretely present in any and every form of human well-being - that is, it must be grounded in some common critical element that runs through any and all forms of human well-being (or its pursuit); and

d. it must appeal to some aspect of human well-being in which every person has a necessary stake.

Together these conditions do not constitute the basis for an ethical norm that offers guidance to individuals in seeking human well-being or in fulfilling obligations to others. Particularly, they do not constitute a basis for norms that one would employ primarily in evaluating people and institutions within a capitalist system. Rather, they constitute the basis for an ethical norm that regulates conduct so as to establish conditions that secure and maintain the possibility of individuals pursuing their own form of well-being and engaging in moral activity among others.

Such a norm is an ethical principle whose function is primarily political or legal. This ethical principle is not used to guide conduct in

\footnotetext{
${ }^{9}$ This is only part of the list developed. (See Rasmussen and Den Uyl, 2005, p.272.)
} 
pursuit of well-being or moral activity because it does not consider the particular situation, culture, or nexus ${ }^{10}$ of persons. Rather, this ethical principle's function is to provide the structural framework (or backdrop) that provides the general social context for the pursuit of one's well-being. Such a principle is an ethical metanorm.

Simply put, liberalism is a political philosophy of metanorms. Yet, this claim is seldom understood or appreciated. One recent author, for example, tells us that liberalism is a "normative political philosophy, a set of moral arguments about the justification of political action and institutions" (Kymlicka, 1989, p.9). Another writer tells us that there is an "opposition... between liberal individualism in some version or other and the Aristotelian tradition in some version or other" (MacIntyre, 1981, p.259). In both cases, we see liberalism treated as an ethical philosophy to be contrasted with other ethical philosophies. $^{11}$

Herein lies much of the problem. Norms are not, in fact, all of one type, differentiated by subject or thinker alone. It may be that some norms regulate the conditions under which moral conduct may take place, while others are more directly prescriptive of moral conduct itself. In light of this possibility, it is not appropriate to say that liberalism is a "normative political philosophy" in the usual sense. As said, liberalism is a political philosophy of metanorms. It seeks not to guide individual conduct in moral activity, but rather to regulate conduct so that conditions might be obtained where moral action can take place. To contrast liberalism directly with alternative ethical systems or values is, therefore, something of a category mistake. Such a move assumes an isomorphic relationship between the ethical and the political, which is precisely what liberalism is trying to alter. ${ }^{12}$

10 The term "nexus" refers to that set of circumstances, talents, endowments, interests, beliefs, and histories that descriptively characterize the individual.

${ }^{11}$ Of course, nothing could be further from the truth than saying that liberalism and Anistotelianism are necessarily opposed. MacIntyre is right, however, to the extent that the "opposition" would be greater without the metanormative distinction.

12 These last two paragraphs are taken from Norms of Liberty (Rasmussen and Den Uyl, 2005, pp.33-34). 
IV. Individual rights are metanorms, and the political/legal institutions of capitalism - that is, the institutions of private property, sanctity of contract, free exchange, and the pursuit of profit - are their real-world manifestations.

As we argue in Norms of Liberty, seeking to protect the possibility of self-directed action - that is, protecting the possibility of exercising practical reason - in a social context is the only thing that satisfies the criteria for solving liberalism's problem. By establishing the political/legal structural conditions that protect the possibility of selfdirection, ${ }^{13}$ we

a. do not structurally favor or prejudice one version of human well-being over any other, because it is the exercise of practical reason that is being protected, not the achievement of its object;

b. protect something that is not only common to, but also required by, every form of human well-being. Every form of human well-being or moral activity involves the exercise of practical reason;

c. protect something that is concretely present in every form of human well-being. It is through the exercise of practical reason that generic goods and virtues achieve reality, determinacy, and value for an individual, and it is through the agency or self-direction of the individual that practical reason functions;

d. protect an aspect of human well-being in which every individual has a necessary stake. Every form of human well-being necessarily involves exercising practical reason; and

e. recognize that each and every individual ought to pursue and achieve their own form of well-being and not act in self-sacrificial ways.

Now, protecting the possibility of the exercise of practical reason in a social context is not central to normative ethics, because normative ethics is concerned with the right or appropriate use of practical reason, but it is vital in solving liberalism's problem. The questions that constitute liberalism's problem are different from the questions that constitute normative ethics, and so the ethical principles that are required for solving liberalism's problem are not reducible to the ones that are required for solving the issues faced in normative ethics. Protecting the possibility of self-direction in a social context is, then, the ethical basis for solving liberalism's problem.

${ }^{13}$ Self-direction is "the act of using one's reason and judgments upon the world in an effort to understand one's surroundings, to make plans to act, and to act within or upon those surroundings" (Rasmussen and Den Uyl, 2005, p.89). 
Self-directed action cannot exist when some persons direct others to purposes to which they have not consented. Moreover, since the initiation of physical force is the single most basic and threatening encroachment upon self-direction, the purpose of the individual right to liberty is to forbid legally such activity in all its forms. The individual right to liberty allows each person a sphere of freedom - a "moral territory" - whereby self-directed activities can be exercised without being invaded by others. This translates socially into a principle of compossible and equal freedom for all. ${ }^{14}$

The freedom must be equal, in the sense that it must allow for the possibility of diverse modes of human well-being, and, therefore, must not be biased structurally in favor of some forms of well-being over others. The freedom must be compossible, meaning that the exercise of self-directed activity by one person must not encroach upon or reduce that of another. Thus, a theory of individual rights that protects the selfdirection of persons can be used to create a political/legal order that will not necessarily require that the well-being of any person or group be sacrificed to any other.

It is important to realize that the individual right to liberty is not directly concerned with the promotion of human well-being itself, but only the condition for its possibility. It is thus not the consequences per se that determine when someone's liberty is violated. What is decisive is whether the action taken by one person toward another secures that other's consent or is otherwise a function of that other's choices. For one might violate another's rights and produce a chain of events that lead to consequences that could be said to be to that other's apparent or real benefit. Alternatively, one might not violate another's rights and produce a chain of events that lead to one's apparent or real detriment. Yet, since the purpose here is to structure a political principle that protects the condition for the possibility of human well-being among others - as understood in terms of "liberalism's problem" - rather than leading to human well-being itself, the consequences of actions are of little importance (except insofar as they threaten the condition which rights were designed to protect in the first place). The concern here is not with how acts will turn out, but rather with setting the appropriate foundation for the taking of any action in the first place.

\footnotetext{
14 This paragraph and the following four are adapted from Norms of Liberty
} (Rasmussen and Den Uyl, 2005, pp.89-92). 
It must be emphasized that the right to liberty - and individual rights in general - are not norms in the sense of guiding us towards the achievement of human well-being or moral excellence. And contrary to appearances, they are not ordinary interpersonal normative principles either. Individual rights express a type of moral principle that must obtain if we are to reconcile our need for sociality in its widest sense with diverse self-directed forms of human wellbeing. In other words, we need a robust social life, but we also need to succeed as individuals approaching a particular form of well-being.

Norms and obligations that specify how to live, both with respect to achieving one's own goals and with respect to living among others, are one thing; norms that define the setting for such interactions and obligations are quite another. The "obligations" one has to another in the latter case are due to a shared need to act in a peaceful and orderly social/political context. These are metanorms. The obligations one has in the former case are a function of what is needed to live well and cannot be generated apart from the particular actions, context, culture, traditions, intentions, and practices in which one finds oneself acting. Those actions and contexts call forth evaluative norms by which success, propriety, and merit can be measured and judged in particular cases. Individual rights are metanorms. They are not, however, called upon by the progress of a culture or an individual, but rather depended upon. As such, individual rights are politically and legally primary.

\section{Business ethics is not business bashing, and providing ethical support for the institutions that define business activity does not imply that there is no such thing as business ethics.}

Individual rights may be metanorms that provide the ethical support for the institutions that provide the context for business activity. Nevertheless, the very point of speaking of metanorms is to provide the context for the application of the insights from normative ethics. Therefore, there is plenty of room for the discussion of ethics in business even if there is ethical support for the institutions that define business activity.

One effect of our foregoing remarks has been to suggest that in a world where rights are not understood as metanorms and where "liberalism's problem" is not at the center of one's understanding of political philosophy, there is very little room for something distinctively called "business ethics." We make this claim because only where political philosophy allows for a distinction between 
norms and metanorms is it possible to have a sphere of moral understanding distinct from the political. As it stands now, business ethics is little more than a slightly specialized version of political philosophy, and the basic theories of political philosophy inform almost completely the various approaches to business ethics. This traditional or usual approach to business ethics is applicable to both ideologies of the "left" and the "right." The propensity to adopt a framework of free markets and stockholder supremacy may be as much informed by the same mistake as an approach which advocates governmental control and stakeholder theories. That basic mistake is to assume that all norms have the same ontological and functional status, differing only in degrees of "priority." We define this position elsewhere (Rasmussen and Den Uyl, 2005, 2008) as "equinormativity." Both the left and the right may accept equinormativity, thus essentially reducing business ethics to a single sort of moral problem, namely, what set of normative principles should govern social life? The "right" answers with something like maximal liberty while the "left" answers in terms of equality or fairness. Business ethics then is understood in terms of, and measured by, its contributions to one of these political philosophical frameworks.

By contrast, if we see political philosophy as essentially concerned with recognizing the centrality of liberalism's problem, making political philosophy a matter of considering the appropriate metanorms, then it is conceivable that business ethics could be a normative field quite distinct from questions of metanormativity (and thus political philosophy) and containing its own set of problems, principles, and normative conclusions. The framework in which business ethics (and any institutional ethics) would operate would, of course, be the metanormative, but its concerns would be entirely different, and discussions of business ethics could not be reduced to issues of metanormativity. If, on the other hand, one's posture toward political philosophy is to deny the centrality of liberalism's problem and to embrace equinormativity, ${ }^{15}$ then finding a distinctive domain for business ethics becomes increasingly problematic.

For the preceding reason, we believe our approach "makes room" for business ethics. Yet, if there is something distinctive about

${ }^{15}$ Equinormativity assumes that all ethical norms are of the same type and have the same function. 
business ethics, it would have to be connected to what is distinctive about business as an activity. Strangely enough, many texts on business ethics simply proceed as if everyone understands what business is (e.g., it somehow concerns "corporations"). When business is defined, the definitions simply presuppose the approach to political philosophy we have rejected above. In one text, for example, business is said to be "a complex fabric of human relationships - relationships between manufacturers and consumers, employers and employees, managers and stockholders, members of corporations and members of the communities in which those corporations act" (Hoffman and Moore, 1990, p.1). Besides giving us no clue as to what links all these paired relations together, ${ }^{16}$ the "definition" is so open-ended and inclusive as to incorporate the whole of society, thus making business ethics simply a species of political or social theory. We have little doubt that the authors of this way of looking at business were quite pleased with such a result, but it merges business ethics into social ethics, making business ethics an example, not a separate subject area.

In another text we're told that "the question of what business per se is, and what its proper concern is, is a social question, one that must be answered in a social context....Business is a social enterprise. Its mandate and limits are set by society" (DeGeorge, 1986, pp.10-11). Like the previous example, this definition either begs all the important questions in political theory or is simply platitudinous. Of course, we cannot beg the question either, but the earlier parts of this paper are meant, as we noted, to address the main points of political philosophy. To say that "society" defines "business" (or any other activity) is simply to say it is nothing in itself and could be defined any way. That is little help in identifying a special subject of business ethics. Now that we have opened up the possibility for the distinctive subject area of business ethics, how can we define "business" in such a way that we can begin to properly think about an ethics in relation to it?

On this score, we need not make any claims to originality. The best definition we have found is offered by Elaine Sternberg: "the

${ }^{16}$ Hoffman and Moore go on to mention the relations as being "economic" but then immediately mention that they are moral as well, leaving open the possibility of an infinite number of characterizations and thus no specialized way to group the named relations. 
defining purpose of business is to maximize owner value over the long term by selling goods or services" (Sternberg, 2000, p.32). What this definition may imply by way of an ethics is well worked out by Sternberg in her book. Our task in closing our remarks here is to say a few things about the salient features of this definition.

One first of all realizes that this definition does not cover everything that one might do. It is not so connected with everything in one's social environment that we must leave it up to "society" to tell us which among our activities qualifies as "business." One's charitable or family activities are not covered by this definition. Indeed, not even all of one's commercial activities are covered, for the definition does not apply to one as a consumer. At the very least, then, we can carve out an area for business ethics that is not reducible to a version of political philosophy and may have some uniquely specifiable norms connected with it. ${ }^{17}$ The first main term to focus upon after realizing these general characteristics is "maximize." Let's skip over that term for just a moment and focus first upon "owner." Owner is a complicated term carrying with it notions of property and proprietary relationships. In this respect, it is likely to be tied into various legal and social relations that define specific rules for determining when one is an owner or the agent of an owner. Whatever those specific rules and relations may be, the point here is that one owns something, even if all one owns is one's own labor. The implications of an ability to exclude and to dispose freely are contained in the idea of ownership. Given that, we can say very fundamentally that business ethics is addressed primarily and essentially to owners.

Going back now to the first term, we learn that business is about maximizing something. This in itself suggests that whatever is being pursued is not being pursued in a partial or deferential way. We might expect, therefore, that norms calling for such limitations on the pursuit of value would be rather contrary to the nature of business. Of course, what is being maximized here is "owner value." Because we are talking about ethics, this is the term in the definition that might be called the "responsibility locator." In the previous definitions cited above, the responsibility locator was essentially "society." Here responsibility falls squarely on the shoulders of

\footnotetext{
${ }^{17}$ Sternberg outlines a number of the general normative parameters right after offering the cited account of what it means to be a business.
} 
owners. This locus of responsibility suggests that the risks and the burdens - as well as the benefits - are to be borne by the owners. They may solicit others in the pursuit of their ends, but the ultimate spring of responsibility is the individual owner.

The owner is also doing something in particular, and this definition suggests that the principal thing the owner is doing is "selling." One may think that owners also buy, and while that is true, it is a derivative and instrumental function. If owners buy, they do so in order finally to sell. That in part is what differentiates a business person from a consumer. Consumers buy. They may also sell, but they do so in order to buy more. Consumers and business persons are both "traders," which explains why the term "trader" is too broad for this definition. Of course, to other sellers a given seller (business person) may look like (and is) a buyer (consumer). That is a matter of perspective. But again, the responsibility locator tells us that the perspective we need to take here is that of the owner. The owner as a business person is a seller. ${ }^{18}$ One other thing to notice is that the owner/seller is making offers "over the long run." We understand the point here to be that the owner/seller is making iterated trades. One exchange to maximize value for an owner does not a business make. We recognize this when we speak of someone being in business.

That seller/owner is offering something, and as the definition specifies, the seller/owner is offering "goods or services." The "or" in "goods or services" may be either inclusive or exclusive, but the main point is that something is offered to others that the owners hope will be of value to them and from which value will be returned to the owner. What is sold may be tangible (e.g., a product) or intangible (e.g., advice), but what is offered is offered with the expectation of a return of value greater than any alternative use of the resources that go into the offering itself. If the owner had another better alternative, but chose this one, the owner would not be maximizing. Any fiduciaries to owners must, therefore, also consider what would maximize for the owner they represent. That is what it means to be a fiduciary. It is important to note, however, that the

18 Sternberg notes that "selling" includes leasing, renting, and the like (Sternberg, 2000, p.217). 
returned value to an owner need not always be in monetary form. Because of the "place holder of value" nature of money, money is the preferred medium of the return of value since it does not define the end to which it is put. Moreover, its objective properties make it easiest for all parties to work with in calculating value. But it is conceivable that owners may take less money for some offering if they are gaining more of something else they might value, e.g., the approbation of their peers, the excitement of the deal, or an initial investment in the anticipation of a greater gain later. The point, though, is that those calculations belong with the owner and no one else.

Each of the terms of the Sternberg definition, as well as the definition as a whole, will raise interesting questions about the appropriate ethical norms and guidelines. In a world where business relationships are intricate and multi-faceted, some of the issues may become very complex. While the approach we have taken here may rule out in principle any calls for the sacrifice of owners' pursuit of maximal value to others or to society, it does not thereby mean that owners are exempt from paying for services they receive from others (or society), nor does it mean that owners need not be concerned about broader social issues than simply the "bottom line." As we noted, however, our concern here is not with these issues. Our concern has been to define a specific sphere of inquiry within which we can explore the sorts of obligations and recommendations that a business person might need to consider. In doing this, we have made a simple assumption: knowing what a business is is necessary for understanding the ethical obligations and recommendations appropriate to it. We "make room for business ethics" by first understanding what essentially characterizes its subject matter. The other thing we needed to do, and which we did in the earlier parts of the paper, is to provide a context in which business ethics can be understood in its own unique way. With these preliminaries, then, one is now ready to launch into an investigation of business ethics.

\section{References}

Aquinas, Thomas. 1981. Summa Theologiae, trans. English Dominicans. New York: Christian Classics.

Beauchamp, Tom L., and Norman E. Bowie. 2003. Ethical Theory and Business. Englewood Cliffs, NJ: Prentice Hall. 
Bradley, Jr., Robert L. 2009. Capitalism at Work: Business, Government, and Energy. Salem, MA: M \& M Scrivener Press.

Brock, Gillian. 1998. "Are Corporations Morally Defensible?" Business Ethics Quarterly 8: 703-721.

DeGeorge, Richard T. 1986. Business Ethics: Second Edition. New York: Macmillan Publishing Co.

Donaldson, Tom. 1982. Corporations and Morality. Englewood Cliffs, NJ: Prentice-Hall.

Donaldson, Tom, Patricia Werhane, and Margaret Cording. 2001. Ethical Issues in Business: Englewood Cliffs, NJ: Prentice Hall.

Hoffman, Michael, W., and Jennifer Mills Moore. 1990. "General Introduction: Ethical Frameworks for Application in Business." In Business Ethics: Readings and Cases in Corporate Morality, ed. Michael W. Hoffman and Jennifer Mills Moore, 1-11. New York: McGraw-Hill Book Co.

Kymlicka, Will. 1989. Liberalism, Community, and Culture. Oxford: Clarendon Press.

Machan, Tibor R. 2007. The Morality of Business: A Profession for Human Wealth Care. New York: Springer.

Machan, Tibor R., and James E. Chesher. 2002. A Primer on Business Ethics. Lanham, MD: Rowman and Littlefield.

MacIntyre, Alasdair. 1981. After Virtue, 2nd ed. Notre Dame, Indiana: University of Notre Dame Press.

Nozick, Robert. 1974. Anarchy, State, and Utopia. New York: Basic Books.

Rasmussen, Douglas B., and Douglas J. Den Uyl. 2005. Norms of Liberty: A Perfectionist Basis for Non-Perfectionist Politics. University Park, PA: Pennsylvania State University Press.

Rasmussen, Douglas B., and Douglas J. Den Uyl. 2008. "Norms of Liberty: Challenges and Prospects." In Reading Rasmussen and Den Uyl: Critical Essays on Norms of Liberty, ed. Aeon J. Skoble, 177-244. Lanham, MD: Lexington Books.

Shaw, William H., and Vincent Barry. 2006. Moral Issues in Business. Belmont, CA: Wadsworth.

Sternberg, Elaine. 2000. Just Business, 2nd ed. New York: Oxford University Press. 